\title{
Preparation and stabilization mechanism of carbon dots nanofluids for drag reduction
}

\author{
Yi-Ning $\mathrm{Wu}^{1} \cdot$ Yuan $\mathrm{Li}^{1} \cdot$ Meng-Jiao Cao ${ }^{1} \cdot$ Cai-Li Dai ${ }^{1} \cdot$ Long He$^{2} \cdot$ Yu-Ping Yang ${ }^{3}$
}

Received: 27 May 2020 / Published online: 24 September 2020

(c) The Author(s) 2020

\begin{abstract}
During the development of low or ultra-low permeability oil resources, the alternative energy supply becomes a prominent issue. In recent years, carbon dots (CDs) have drawn much attention owing to their application potential in oil fields for reducing injection pressure and augmenting oil recovery. However, carbon dots characterized of small size, high surface energy are faced with several challenges, such as self-aggregation and settling. The preparation of stably dispersed carbon dots nanofluids is the key factor to guarantee its application performance in formation. In this work, we investigated the stability of hydrophilic carbon dots (HICDs) and hydrophobic carbon dots-Tween 80 (HOCDs) nanofluids. The influences of carbon dots concentration, sorts and concentration of salt ions as well as temperature on the stability of CDs were studied. The results showed that HICDs are more sensitive to sort and concentration of salt ions, while HOCDs are more sensitive to temperature. In addition, the core flooding experiments demonstrated that the pressure reduction rate of HICDs and HOCDs nanofluids can be as high as $17.88 \%$ and $26.14 \%$, respectively. Hence, the HICDs and HOCDs nanofluids show a good application potential in the reduction of injection pressure during the development of low and ultra-low permeability oil resources.
\end{abstract}

Keywords Carbon dots $\cdot$ Nanofluids $\cdot$ Drag reduction $\cdot$ Stabilization mechanism $\cdot$ Salt tolerance

\section{Introduction}

With the continuous growth in crude oil demand, unconventional oil and gas resources become increasingly significant (Liu et al. 2017, 2019). Due to the low or ultra-low permeability of the formation, the water-injection pressure is extremely high, increasing the difficulties in the subsequent energy supply and exploitation. Recently, nanofluids with

Handling Editor: Zhen-Hua Rui

Edited by Xiu-Qiu Peng

Yi-Ning $\mathrm{Wu}$

wuyining@126.com

$\checkmark$ Cai-Li Dai

daic1@upc.edu.cn

1 Shandong Key Laboratory of Oilfield Chemistry, School of Petroleum Engineering, China University of Petroleum (East China), Qingdao 266580, China

2 Petroleum Engineering Institute, Northwest Branch of Sinopec, Urumchi 830000, China

3 CNPC Engineering Technology R\&D Company Limited, Beijing 100007, China high thermostability and interfacial activity attract more and more attention (Noreen et al. 2016; Lu et al. 2017). Previous studies have also indicated that nanofluids have shown the application potential in drag reduction, chemical flooding, filtration reducer and so on (Zhao et al. 2018a, b; Ramesh and Prabhu 2011; Soltanipour et al. 2016; Zhong et al. 2011; Mu et al. 2010; Zhao et al.2018a, b; Hwang et al. 2008; Dai et al. 2020; Li et al. 2020; Zhao et al. 2019).

However, for further field application, the instability of nanofluids is an essential problem. The relatively low resistance of silica nanofluids to temperature and salt aggravates the aggregation and precipitation after long-time use, which probably gives rise to the blockage of the pore-throats structure underground causing formation pollution (Das 2009). To overcome this problem, methods for preparing uniform and stable nanofluids are constantly developed ( $\mathrm{Li}$ et al. 2011; Babita and Gupta 2016), including physical and chemical modification methods (Esfandyari et al. 2014; Arulprakasajothi et al. 2015; Wu et al. 2019). Tushar et al. prepared nanofluids by adding polymers (Arulprakasajothi et al. 2015) and proved that polymer can enhance nanofluids stability. Zhou et al. developed alumina polymerized olefin nanofluids by physical modification and the effects of shear 
rate and temperature on the viscosity of alumina polymerized olefin nanofluids were studied (Zhou et al. 2010). The preparation of rice husk ash-derived nanofluids was reported by Zhang et al. and the stability of which was found to be related to $\mathrm{pH}$, dispersant type and concentration (Zhang et al. 2016).

Except for silica nanofluids, the stability of carbonbased nanofluids has also been investigated by many scholars (Chen and Xie 2010; Baratpour et al. 2016; Soleimani et al. 2018). The stabilization effects of cationic gemini surfactants on carbon nanotubes nanofluids were studied by Chen and Xie (2010). It was found that the increase in spacer chain length of cationic gemini surfactant gave rise to the sediment of multi-walled carbon nanotubes (MWNTs for short) in the nanofluids (Chen and Xie 2010). The effects of temperature and solid volume fraction on the dynamic viscosity of single-wall carbon nanotubes in ethylene glycol were investigated by Baratpour et al. (2016). Results revealed that the solid volume and temperature play a key role in the dynamic viscosity and stability of nanofluid. Mirza et al. produced carbon nanotube-based nanofluids and found out the highest stability was obtained at $0.3 \mathrm{wt} \%$ (Soleimani et al. 2018). Despite the satisfactory stability and the enhanced recovery efficiency, the preparation processes of carbon nanotube-based nanofluids is relatively complicated, which is not suitable for large-scale application. In contrast, due to the simple structure, the preparation of carbon dots (CDs) is much easier. Besides, CDs have the advantages of small particle size, high particle size homogeneity, high chemical inertia, easy functionalization, etc. (Jia et al. 2019; Du et al. 2015; Mohammad 2019; Wang and $\mathrm{Hu}$ 2014), making CDs a promising alternative in oil field application.

In this work, both physical and chemical modification methods were applied to improve the dispersion of carbon dots and to obtain stable nanofluids. The effects of carbon dots concentration, ion concentration and temperature on the stability of carbon nanoparticles were evaluated, and the stability mechanism of carbon nanoparticles is revealed. Furthermore, the drag-reduction performance during fluid injection was also analyzed to evaluate the application potential in formation energy replenishment during the development of unconventional oil reservoirs.

\section{Materials and methods}

\subsection{Materials}

Hydrophobic CDs (HOCDs for short) and chemical grafting hydrophilic CDs (HICDs) were synthesized with petroleum coke using the procedure reported previously ( $\mathrm{Wu}$ et al. 2014). In consideration of the hydrophobicity of HOCDs, they cannot be homogenously dispersed in aqueous phase; therefore, HOCDs were mixed with Tween 80 (Purchased from Aladdin Co., Ltd) at a ratio of 1:1 to guarantee the dispersity for the preparation of nanofluids. The salts used in our experiments included sodium chloride $(\mathrm{NaCl})$, calcium chloride $\left(\mathrm{CaCl}_{2}\right)$ and magnesium chloride $\left(\mathrm{MgCl}_{2}\right)$, which were purchased from Chinese Medicine Group Chemical Reagent Co., Ltd. The preparation methods of HICDs and HOCDs injection nanofluids are as follows: firstly, a certain volume of HICDs and HOCDs-Tween 80 dispersions were added to the beakers, respectively. Then, distilled water was added to the beakers to dilute the suspension to desired concentration. Finally, the dispersions were ultrasonic-bathed for about $10 \mathrm{~min}$ until the dispersion became clear and uniform.

\subsection{Characterization of HICDs and HOCDs}

HICDs and HOCDs nanofluids with a concentration of $0.03 \mathrm{wt} \%$ were prepared. HICDs and HOCDs were characterized by JEM-2100 transmission electron microscopy (TEM) of JEOL, Co., Ltd. The stability of HICDs and HOCDs was evaluated by measuring the particle size under various conditions (salt ions species and temperature). The particle size and zeta potential of HICDs and HOCDs nanofluids were measured by Malvern Zetasizer Nano ZS90 instrument.

\subsection{Core displacement experiments for evaluating drag-reduction performance}

The artificial cores with a permeability of $0.35 \mathrm{mD}$, a length of $5 \mathrm{~cm}$ and a diameter of $2.5 \mathrm{~cm}$ were dried at $90{ }^{\circ} \mathrm{C}$ and weighed. Afterward, the cores were immersed in brine then saturated under subatmospheric pressure for $48 \mathrm{~h}$. The weight after saturation was measured. The saturated cores were mounted in a core holder with a confining pressure of $2 \mathrm{MPa}$. $\mathrm{NaCl}$ solution of $3 \mathrm{wt} \%$ was injected to the core at a flow rate of $0.05 \mathrm{~mL} / \mathrm{min}$. The injected pressure was measured at a time interval of 10 min until reaching a plateau value of $P_{1}$. HICDs or HOCDs nanofluid was injected and the injecting pressure was recorded at the same time. In the last step, $3 \mathrm{wt} \% \mathrm{NaCl}$ solution was reinjected into the core with the injecting pressure recorded. The final pressure was recorded as $P_{2}$. The drag-reduction rate was calculated as: $P \%=\left(P_{1}-P_{2}\right) / P_{1} \times 100 \%$. 


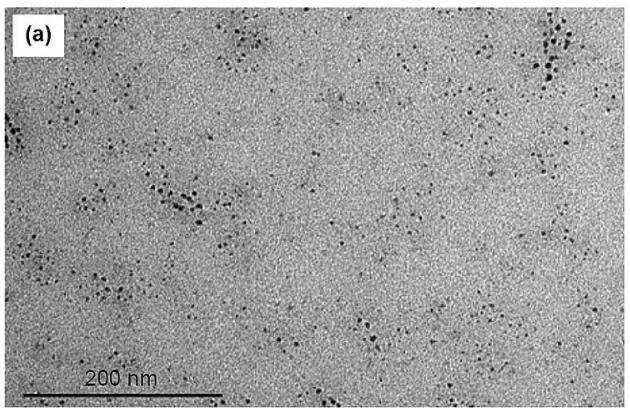

Fig. 1 TEM images of HICDs (a) and HOCDs (b)

\section{Results and discussion}

\subsection{Characterization of HICDs and HOCDs}

The TEM images of HICDs and HOCDs are shown in Fig. 1. As presented, HICDs and HOCDs are both spherical nanoparticles. When the concentration of both HICDs and HOCDs is $0.1 \mathrm{wt} \%$, no obvious agglomeration was observed in the solution, and the particle size was mainly distributed at around $10 \mathrm{~nm}$. The particle size distribution and zeta potential of HICDs and HOCDs nanofluids of different concentrations are shown in Fig. 2. It was found that the average particle size of HOCDs was of $8.88 \mathrm{~nm}$ and zeta potential is about $-6.5 \mathrm{mV}$, while the average particle size of HICDs was of $12.88 \mathrm{~nm}$ and zeta potential is about $-36.5 \mathrm{mV}$. The particle size measured by dynamic light scattering is in good agreement with the corresponding TEM observations.

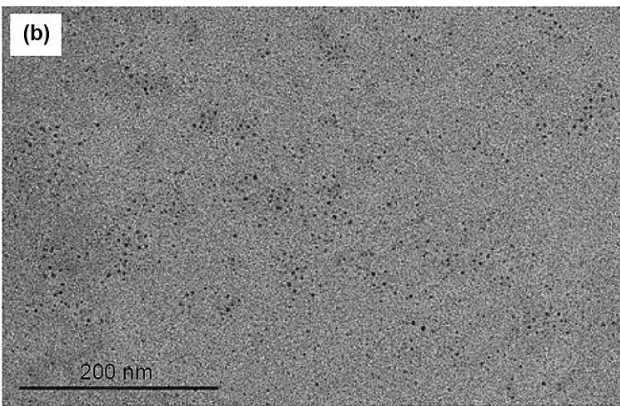

\subsection{The influence of nanoparticle concentration on the stability of nanofluids}

The particle size and zeta potential of HICDs and HOCDs nanofluids with different concentrations were measured. The results are shown in Fig. 2. The particle sizes of both HICDs and HOCDs nanofluids increased with the increase in nanoparticle concentrations. For HICDs, the size changed from 12 to $19 \mathrm{~nm}$, and for HOCDs, the size varied from 8 to $26 \mathrm{~nm}$ with concentration increasing from $0.03 \mathrm{wt} \%$ to $0.3 \mathrm{wt} \%$. The particle size investigated was smaller than $30 \mathrm{~nm}$ when the concentration falls within the scope of the study, indicating no severe agglomeration in HICDs and HOCDs nanofluids. The absolute zeta potential value of HICDs remained basically stable with the increase in concentration ranging over $36.5 \mathrm{mV}-25.0 \mathrm{mV}$. For HOCDs, the particle surface was close to being electrical neutral and nanoparticles were dispersed by nonionic surfactants. Thus, the absolute zeta potential value of HOCDs was lower than that of HICD and remains at a certain level as concentration increases. According to DLVO theory and previous works, the zeta potential of nanoparticles is the key to stability of nanofluids. Higher
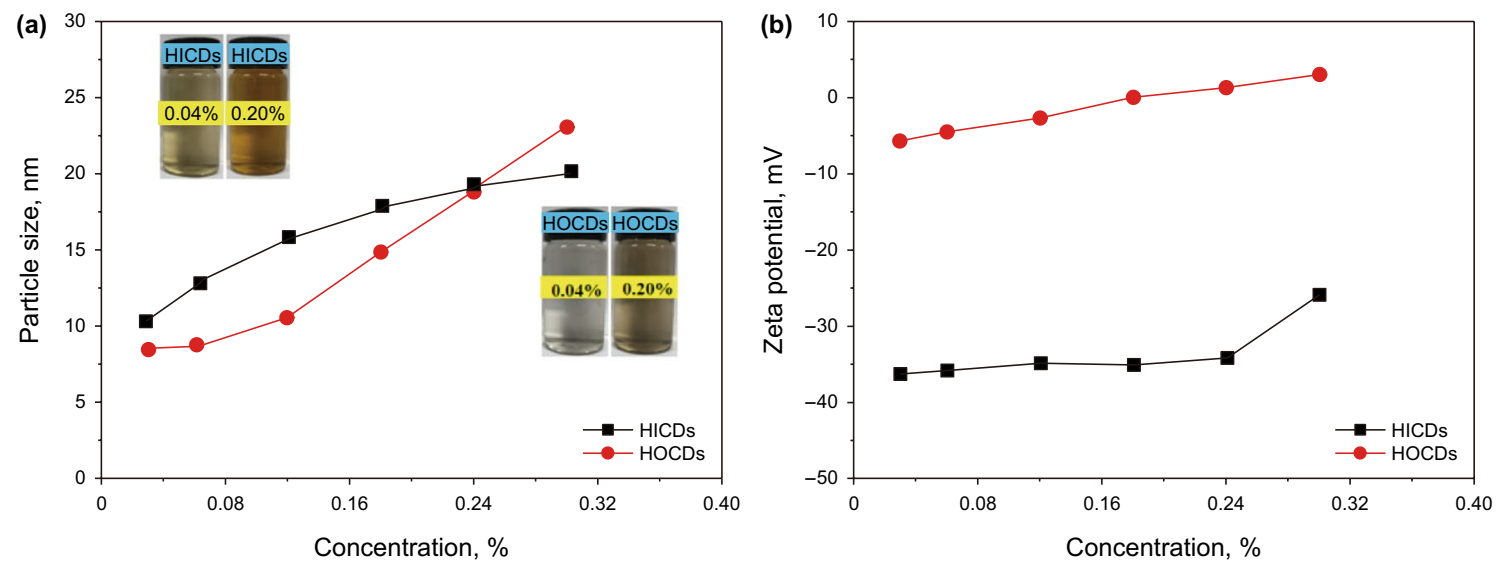

Fig. 2 Effect of concentration of HICDs (black square) and HOCDs (red circle) nanofluids on a particle size and b zeta potential 
absolute zeta potential value is favorable for the stability of nanofluids without additional salt. With the increase in concentration, the absolute zeta potential of HICDs and HOCDs decreases gradually. The electrostatic repulsive force between nanoparticles decreases with the increase in CDs concentration. In addition, the collision probability of carbon dots increases with the increase in CDs concentration, which will increase the probability of particle aggregation, resulting in a decrease in the stability of nanofluids. Comparatively speaking, HICDs is not particularly sensitive to concentration. Hence, the stability of HICDs is better than that of HOCDs in high concentrations.

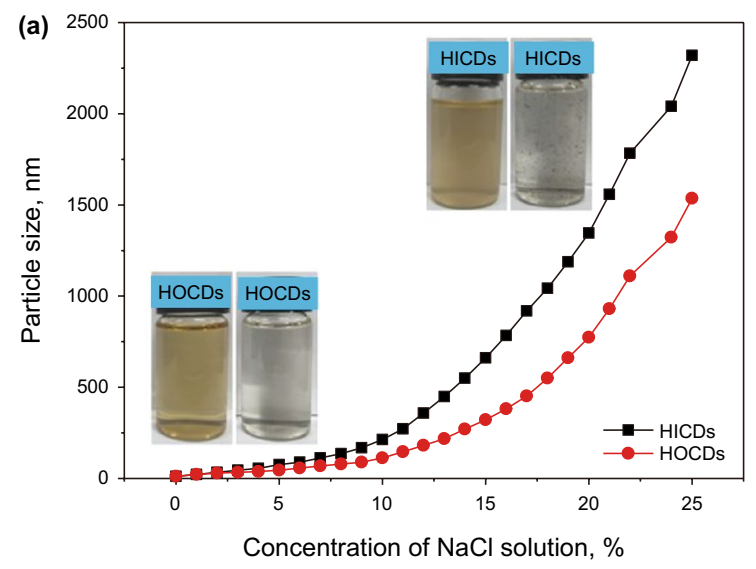

\subsection{The influences of salt concentration on the stability of HICDs and HOCDs nanofluids}

Salt resistance of HICDs and HOCDs nanofluids was investigated in this part. The effects of $\mathrm{NaCl}$ on the stability of HICDs and HOCDs nanofluids were evaluated in first place. The results of particle size and zeta potential are shown in Fig. 3. The particle size of both HICDs and HOCDs nanofluids increased with the augmentation of $\mathrm{NaCl}$ concentration. This indicates the stability of HICDs and HOCDs nanofluids decreases with the increase in $\mathrm{NaCl}$ concentration. When the concentration of $\mathrm{NaCl}$ is less than $10 \mathrm{wt} \%$,

Fig. 3 Effect of $\mathrm{NaCl}$ concentration on $\mathbf{a}$ particle size and $\mathbf{b}$ zeta potential
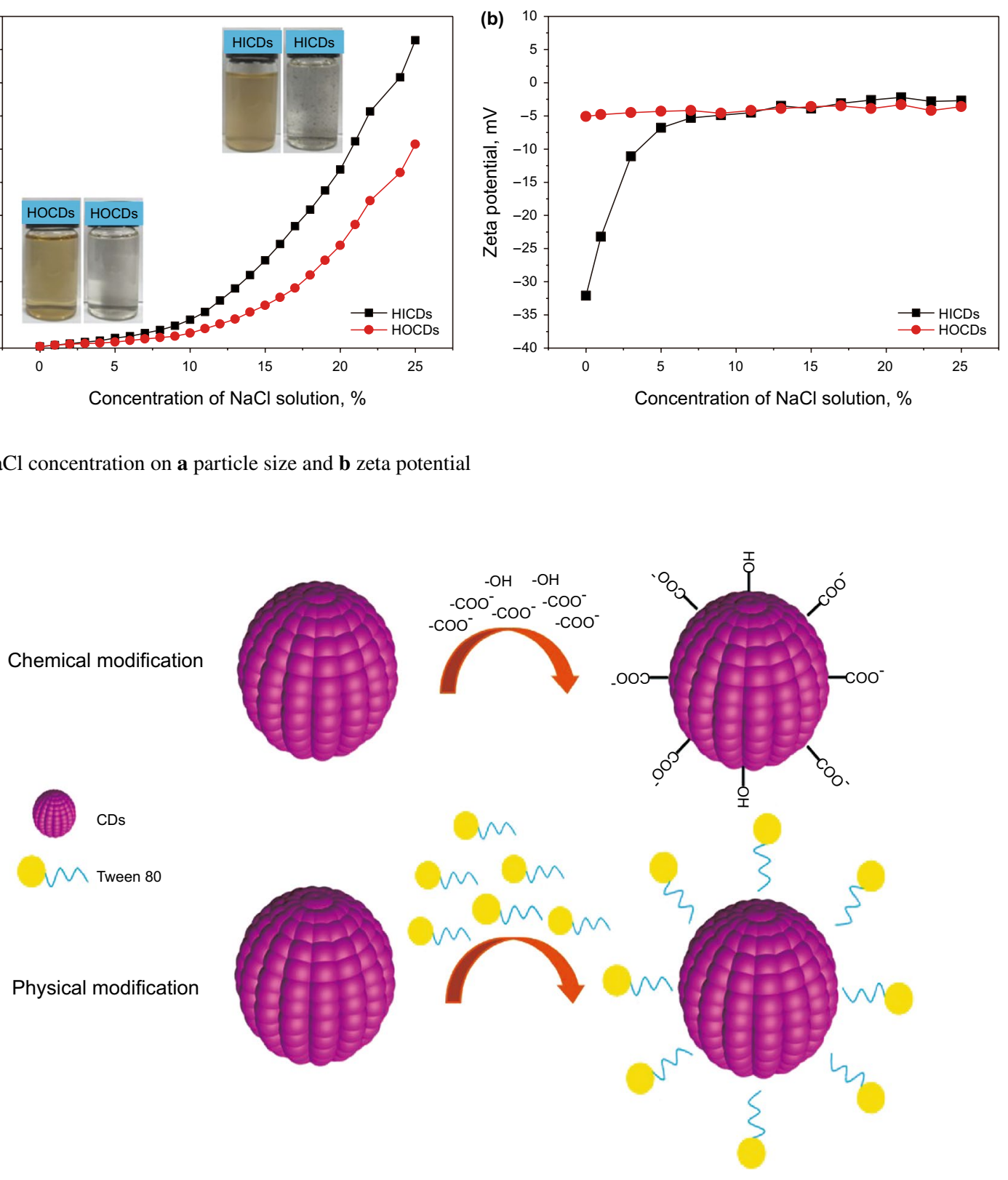

Fig. 4 The image of structures of HICDs and HOCDs 
the sizes of the two kinds of particles were similar. When $\mathrm{NaCl}$ concentration is over $15 \mathrm{wt} \%$, the particle size of HICDs was larger than that of HOCDs. As the concentration of $\mathrm{NaCl}$ solution increases, the absolute value of zeta potential for both HICDs and HOCDs nanofluids decreased. The change of zeta potential was more obvious in HICDs nanofluids. When the concentration of $\mathrm{NaCl}$ is lower than $10 \mathrm{wt} \%$, the absolute zeta potential of HICDs decreased significantly with the addition of $\mathrm{NaCl}$. The cause for the results is the surface physicochemical property of the carbon dots. Figure 4 shows the schematic diagrams of HICDs and HOCDs surface structures. The surface of HICDs carries a large number of negatively charged groups after oxidation. HOCDs were dispersed in water by adding Tween 80 -a nonionic surfactant which can easily adsorb on the surface of HOCDs. The adsorption layer of Tween 80 increases the hydrophilicity. Thus, it can be seen that HICDs alone can resist the aggregation in aqueous phase without salt by virtue of the negative functional groups. However, the electrostatic double layer of HICDs is compressed after adding a certain amount of $\mathrm{NaCl}$. Hence, the stability of HICDs is more sensitive to $\mathrm{NaCl}$ concentration. In contrast, HOCDs were coated with Tween 80 and remained in an uncharged condition. The change of zeta potential of HOCDs nanofluids is not significant. The absolute value of zeta potential of HOCDs nanofluids without $\mathrm{NaCl}$ and with $\mathrm{NaCl}$ presented was always smaller than $7.5 \mathrm{mV}$. With the protection of the nonionic surfactant, HOCDs nanofluids are superior to HICDs nanofluids in $\mathrm{NaCl}$ tolerance.

The effects of $\mathrm{CaCl}_{2}$ concentration on particle size and zeta potential of HICDs and HOCDs were measured as well. The results are shown in Fig. 5. As the concentration of $\mathrm{CaCl}_{2}$ solution increases, the particle size of HICDs and HOCDs grew continuously. As shown in Fig. 5a, the particle size of HICDs nanofluids increased from 12 to $1474 \mathrm{~nm}$ as

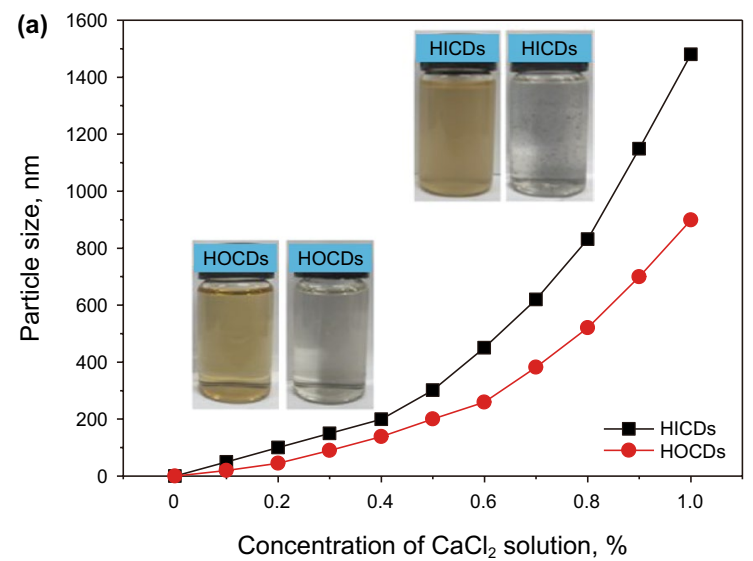

$\mathrm{CaCl}_{2}$ concentration increases from 0 to $1 \mathrm{wt} \%$. The particle size of HOCDs nanofluids increased from about $9 \mathrm{~nm}$ to $847 \mathrm{~nm}$. When the concentration of $\mathrm{CaCl}_{2}$ solution is lower than $0.4 \mathrm{wt} \%$, the particle sizes difference between the two nanofluids investigated was not that significant. However, the particle sizes difference between HICDs and HOCDs nanofluids increased sharply when $\mathrm{CaCl}_{2}$ concentration is higher than $0.4 \mathrm{wt} \%$.

Figure $5 \mathrm{~b}$ shows the absolute value of zeta potential of $\mathrm{CDs}$ at $\mathrm{CaCl}_{2}$ concentrations ranging from 0 to $1 \mathrm{wt} \%$. The absolute value of HICDs zeta potential decreased from 31.5 to $2.9 \mathrm{mV}$, while the absolute value of zeta potential in HOCDs nanofluids kept almost unchanged ranging over $4.8 \mathrm{mV}-7.1 \mathrm{mV}$. When the concentration of $\mathrm{CaCl}_{2}$ solution exceeds $0.4 \mathrm{wt} \%$, the absolute value of zeta potential of HICDs became relatively small leading to the aggregation of HICDs. In addition, the results show the divalent cations dissociated from $\mathrm{CaCl}_{2}$ possess stronger influence on electrical repulsion than monovalent cations from $\mathrm{NaCl}$. Thus, HICDs and HOCDs nanofluids are more sensitive to $\mathrm{CaCl}_{2}$ than to $\mathrm{NaCl}$.

The tolerance of HICDs and HOCDs nanofluids to $\mathrm{MgCl}_{2}$ was also investigated. Figure 6 shows the change of particle size and zeta potential of HICDs and HOCDs nanofluids as the concentration of $\mathrm{MgCl}_{2}$ increases from 0 to $1 \mathrm{wt} \%$. With the increase in $\mathrm{MgCl}_{2}$ concentration, the particle size of HICDs nanofluids increased from 12 to $485 \mathrm{~nm}$. A similar increase can be observed in HOCDs nanofluids with a size change from 8 to $260 \mathrm{~nm}$, indicating that the tolerance of HOCDs to $\mathrm{MgCl}_{2}$ is better than HICDs. Furthermore, the particle size in $1 \mathrm{wt} \% \mathrm{MgCl}_{2}$ solution was less than $500 \mathrm{~nm}$ which is much smaller than that in $1 \mathrm{wt} \% \mathrm{CaCl}_{2}$ solution.

Figure $6 \mathrm{~b}$ shows that when the $\mathrm{MgCl}_{2}$ solution concentration increases from 0 to $1 \mathrm{wt} \%$, the absolute value of zeta potential in HICDs nanofluids changes from 32 to

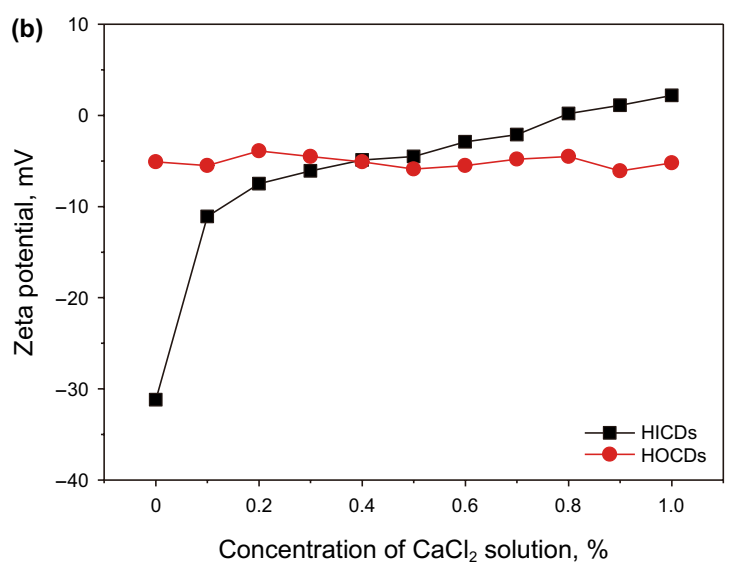

Fig. 5 Effect of $\mathrm{CaCl}_{2}$ concentration on particle size (a) and zeta potential (b) 

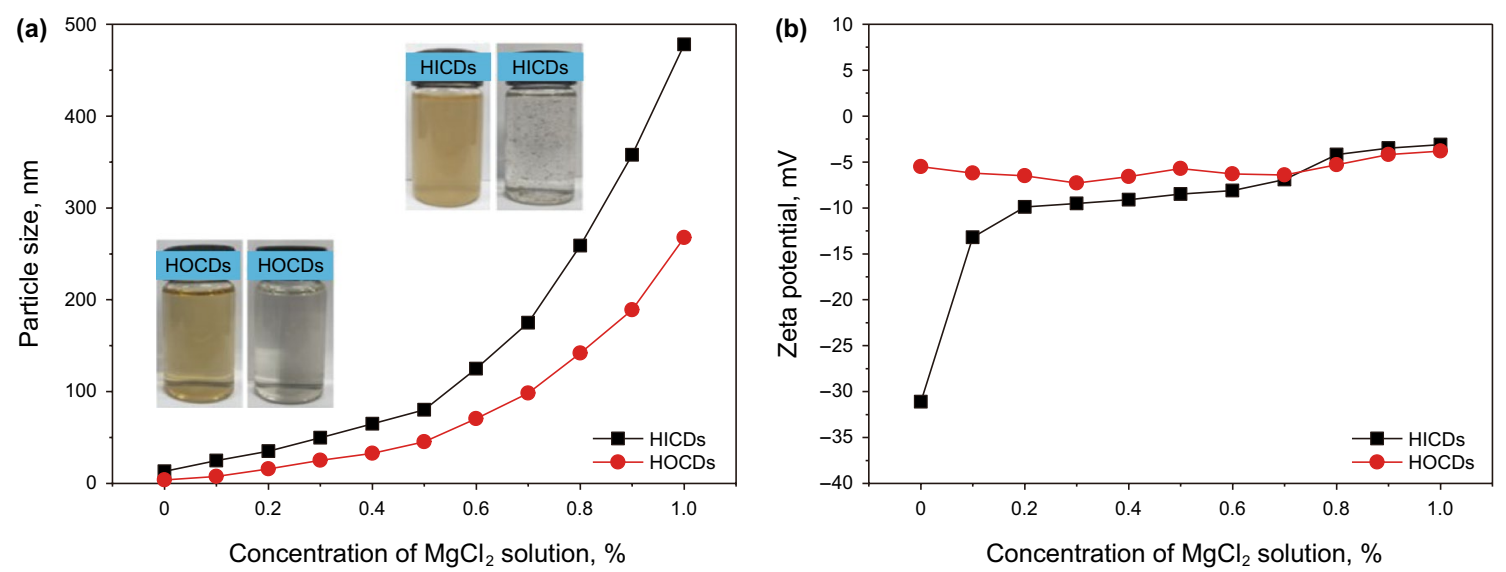

Fig. 6 Effect of $\mathrm{MgCl}_{2}$ concentration on particle size (a) and zeta potential (b)

$4.8 \mathrm{mV}$, and that of HOCDs nanofluids changes from 5.3 to $5.0 \mathrm{mV}$. When the concentration of $\mathrm{MgCl}_{2}$ is higher than $0.2 \mathrm{wt} \%$, the zeta potential of HOCDs nanofluids and HICDs nanofluids is similar, which means that the stability is almost the same. In summary, the stability of HOCDs nanofluids is better than HICDs nanofluids with the presence of $\mathrm{MgCl}_{2}$. Although the magnesium ions and calcium ions are of divalent, the influence of magnesium ions to surface charge density is less significant than that of calcium ions. As a result, HICDs and HOCDs are less sensitive to $\mathrm{MgCl}_{2}$ than to $\mathrm{CaCl}_{2}$.

\subsection{The influence of temperature on the stability of HICDs and HOCDs nanofluids}

To evaluate the effect of temperature on the stability of HICDs and HOCDs nanofluids, $0.1 \mathrm{wt} \%$ of HICDs and HOCDs nanofluids was applied. The particle size and zeta potential of HICDs and HOCDs nanofluids were measured from 30 to $90{ }^{\circ} \mathrm{C}$, and the results are shown in Fig. 7. The particle sizes of HICDs and HOCDs nanofluids modestly increased with temperature, showing satisfactory temperature-resistant performances of both nanofluids investigated. Similarly, the variation trend of zeta potential is not significant.

Meanwhile, the particle size and zeta potential of HICDs and HOCDs nanofluids were measured at $90{ }^{\circ} \mathrm{C}$ with a storage time of $50 \mathrm{~h}$. The particle size and zeta potential measured are shown in Fig. 8. The results show that the particle size of HICDs nanofluids modestly increased in $50 \mathrm{~h}$, while the particle size of HOCDs nanofluids changes from 8 to $17 \mathrm{~nm}$. The temperature resistance of HICDs nanofluids is superior to that of HOCDs nanofluids. The absolute value of zeta potential of HOCDs nanofluids and HICDs nanofluids kept almost constant with HOCDs around $6 \mathrm{mV}$, and HICDs around $30 \mathrm{mV}$. Hence, the tolerance of HOCDs nanofluids to temperature that is inferior to HICDs nanofluids may be related to hydrogen bonds. The surface of
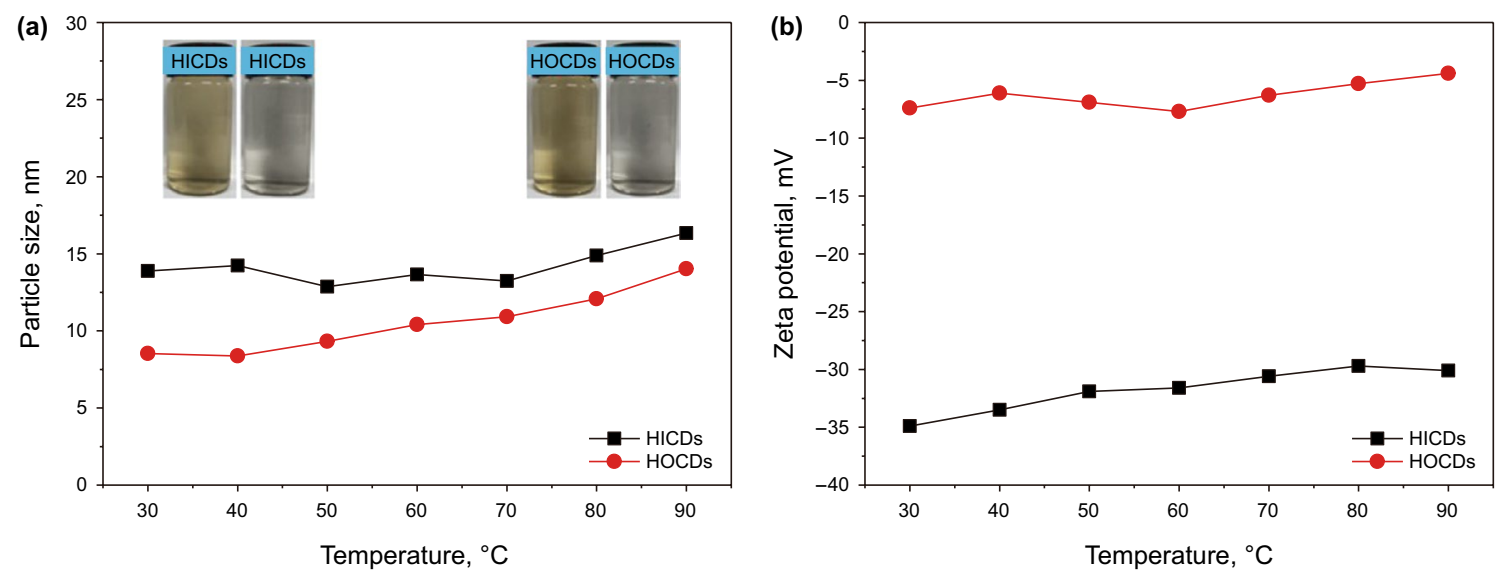

Fig. 7 Effect of different temperatures on particle size (a) and zeta potential (b) 


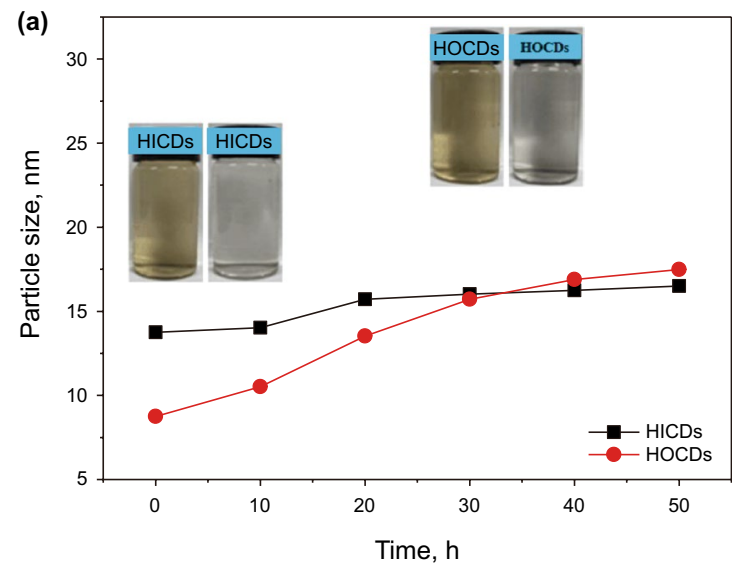

Fig. 8 Effect of time at $90{ }^{\circ} \mathrm{C}$ on a particle size and $\mathbf{b}$ zeta potential

HOCDs nanofluids covers with Tween 80 which will form hydrogen bonds with water facilitating the distribution of HOCD. However, hydrogen bonds will be weak at relatively high temperature. In contrast, HICDs with amount of surface charges are less affected by the temperature, whose thermal stability is relatively high.

\subsection{Drag reduction of HICDs and HOCDs nanofluids}

The experimental processes to evaluate drag-reduction performances of HICDs and HOCDs consist of three stages: first stage injecting brine water, then injecting HICDs or HOCDs nanofluid flooding, finally injecting brine again as shown in Fig. 9. At the first brine flooding stage, the injection pressure first increased gradually with the increase in the volume injected into the core, followed by a platform at about $1610 \mathrm{kPa}$. Then, nanofluid is injected. The pressure

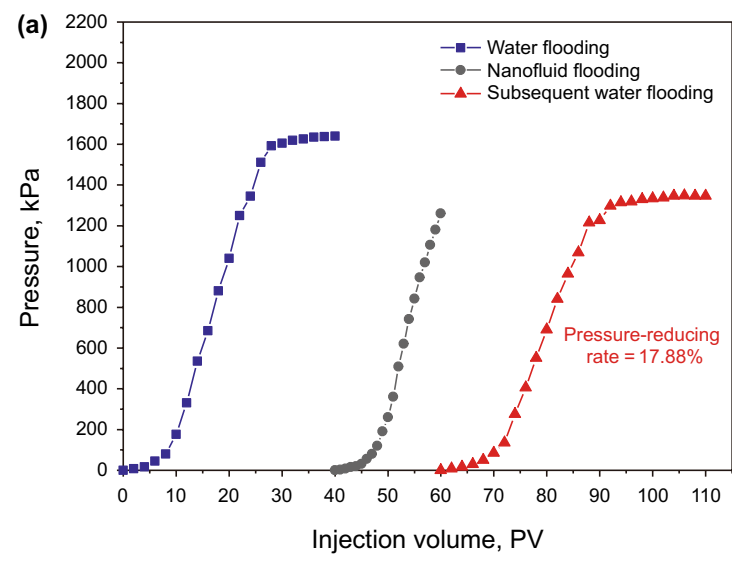

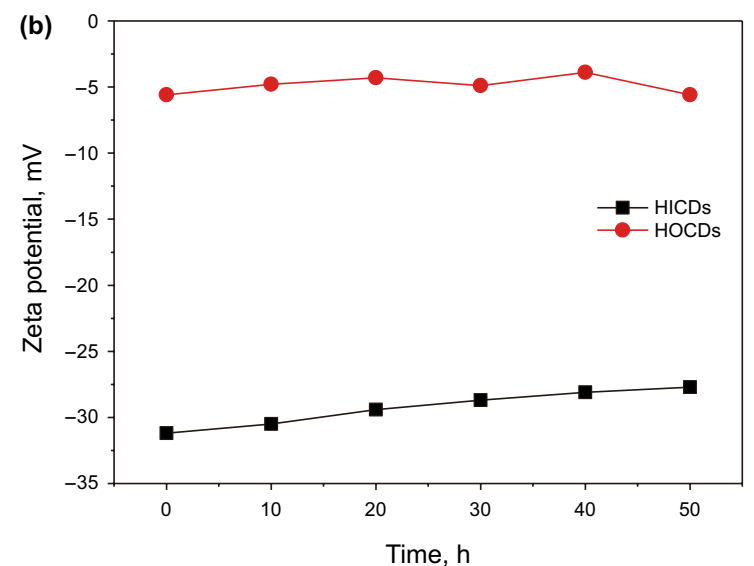

increases continuously with the volume injected. The injection pressure of HOCDs nanofluid is relatively smaller than the one of HICDs nanofluid. In the subsequent water flooding, the injection pressure results demonstrate that HOCDs nanofluid has a better pressure reduction effect. The pressure reduction rate of HOCDs nanofluid can be as high as $26.14 \%$, which is larger than that of HOCDs nanofluid. The possible reasons for this phenomenon are related to characteristics of HOCDs. The surface charge of HOCDs is less than HICDs; thus, the adsorption of HOCDs on rock surface is more significant, which may reduce surface roughness of the core. Furthermore, HOCDs are more hydrophobic than HICDs. The wettability of the rock surface may become more hydrophobic after the adsorption of HOCDs; consequently, the hydrophobic slip near rock surface will become more evident. Thus, pressure reduction effect of HOCDs is better than HICDs.

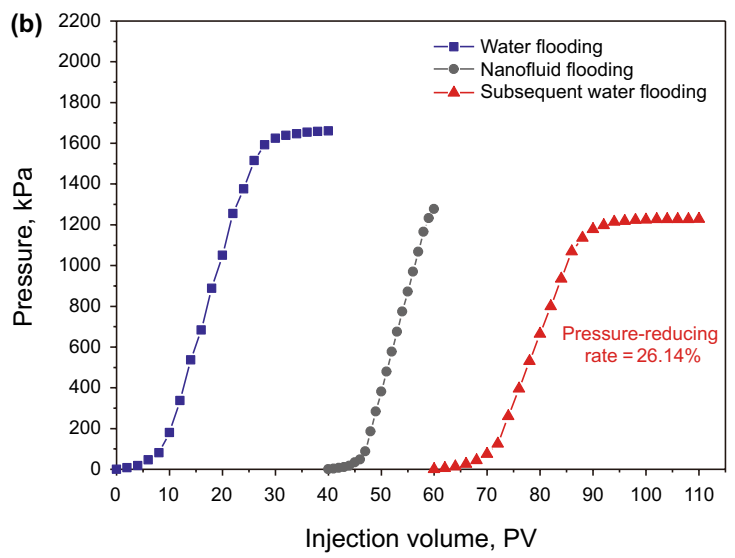

Fig. 9 Injecting pressure change of (a) HICDs and (b) HOCDs nanofluid with water flooding first, then the injection of HICDs or HOCDs nanofluid and subsequent water flooding 


\section{Conclusion}

The work here investigated the stability of two kinds of carbon dots nanofluids, HICDs and HOCDs. The influences of carbon dot concentration, ion strength, cationic ion valence and temperature were evaluated. By analyzing the evolution of particle size and zeta potential, we found that both HICDs and HOCDs possessed similar stability without obvious aggregations when no salt presented. Due to the difference in surface properties, HOCDs show a better salt tolerance than HICDs with the presence of salts. The salt sensitivity of two nanofluids followed the sequence of $\mathrm{NaCl}<\mathrm{CaCl}_{2}<\mathrm{MgCl}_{2}$. The abundant surface charges of HICDs ensured its thermal stability. Furthermore, the pressure reduction rate of HICDs and HOCDs nanofluid can be as high as $17.88 \%$ and $26.14 \%$, respectively. This demonstrates the carbon dots process high drag-reduction performance, which could help resolve the difficulty in energy supply during the development of low permeability oil reservoir. Thus, carbon dots nanofluids show good application potential in oil fields.

Acknowledgements The work was supported by the National Natural Science Foundation of China (51704313) and the Chang Jiang Scholars Program (No. T2014152).

Open Access This article is licensed under a Creative Commons Attribution 4.0 International License, which permits use, sharing, adaptation, distribution and reproduction in any medium or format, as long as you give appropriate credit to the original author(s) and the source, provide a link to the Creative Commons licence, and indicate if changes were made. The images or other third party material in this article are included in the article's Creative Commons licence, unless indicated otherwise in a credit line to the material. If material is not included in the article's Creative Commons licence and your intended use is not permitted by statutory regulation or exceeds the permitted use, you will need to obtain permission directly from the copyright holder. To view a copy of this licence, visit http://creativecommons.org/licenses/by/4.0/.

\section{References}

Arulprakasajothi M, Elangovan K, Hemachandra RK, Suresh S. Experimental study of preparation, characterisation and thermal behaviour of water-based nanofluids containing titanium oxide nanoparticles. Appl Mech Mater. 2015;766-767:348-54. https:// doi.org/10.4028/www.scientific.net/AMM.766-767.348.

Babita SSK, Gupta SM. Preparation and evaluation of stable nanofluids for heat transfer application: a review. Exp Therm Fluid Sci. 2016;79:202-12. https://doi.org/10.1016/j.expthermf1 usci.2016.06.029.

Baratpour M, Karimipour A, Afrand M, Wongwises S. Effects of temperature and concentration on the viscosity of nanofluids made of single-wall carbon nanotubes in ethylene glycol. Int Commun Heat Mass Transf. 2016. https://doi.org/10.1016/j.icheatmasstrans fer.2016.02.008.

Chen L, Xie H. Properties of carbon nanotube nanofluids stabilized by cationic gemini surfactant. Thermochim Acta. 2010;506(1):62-6. https://doi.org/10.1016/j.tca.2010.04.016.
Dai CL, Li Y, Xie QC, Xu K, Hu Y, Zhou ZN, et al. Reduction of clean fracturing fluid filtration loss by viscosity enhancement using nanoparticles: is it feasible? Chem Eng Res Des. 2020;156:414-24. https://doi.org/10.1016/j.cherd.2020.02.017.

Das SK. A review of heat transfer in nanofluids. Adv Heat Transf. 2009;41(08):81-197. https://doi.org/10.1016/S0065 $-2717(08) 41002-X$.

Du W, Xu X, Hao H, Liu R. Green synthesis of fluorescent carbon quantum dots and carbon spheres from pericarp. Sci China-Chem. 2015;58(5):863-70. https://doi.org/10.1007/s 11426-014-5256-y.

Esfandyari A, Junin R, Samsuri A, Piroozian A, Hokmabadi M. Impact of metal oxide nanoparticles on enhanced oil recovery from limestone media at several temperatures. Energy Fuels. 2014;28(10):6255-66. https://doi.org/10.1021/ef5013616.

Hwang Y, Lee JK, Lee JK, Jeong YM, Cheong SI, Ahn YC. Production and dispersion stability of nanoparticles in nanofluids. Powder Technol. 2008;186(2):145-53. https://doi.org/10.1016/j.powte c. 2007.11.020.

Jia H, Leng X, Wang QX, Han YG, Wang SY, Ma A, et al. Controllable emulsion phase behaviour via the selective host-guest recognition of mixed surfactants at the water/octane interface. Chem Eng Sci. 2019;202:75-83. https://doi.org/10.1016/j.ces.2019.03.036.

Li Y, Dai CL, Wu YN, Xu K, Zhao MW, Wang YH. Viscoelastic surfactant fluids filtration in porous media: a pore-scale study. AIChE J. 2020. https://doi.org/10.1002/aic.16229.

Li Y, Xie HQ, Wang JF, Yu W. Study on the preparation and properties of copper nanoparticles and their nanofluids. Adv Mater Res. 2011;399-401:606-9. https://doi.org/10.4028/www.scientific.net/ AMR.399-401.606.

Liu J, Dai Z, Li C, Lv K, Huang X, Sun J, et al. Inhibition of the hydration expansion of Sichuan gas shale by adsorption of compounded surfactants. Energy Fuels. 2019;33:6020-6. https://doi. org/10.1021/acs.energyfuels.9b00637.

Liu PS, Niu LY, Li XH, Zhang ZJ. Environmental response nanosilica for reducing the pressure of water injection in ultra-low permeability reservoirs. J Nanopart Res. 2017;19:390. https://doi. org/10.1007/s11051-017-4086-1.

Lu T, Li ZM, Zhou Y, Zhang C. Enhanced oil recovery of low-permeability cores by $\mathrm{SiO}_{2}$ nanofluid. Energy Fuels. 2017;31:5612-21. https://doi.org/10.1021/acs.energyfuels.7b00144.

Mohammad JM. Carbon quantum dots and their biomedical and therapeutic applications: a review. RSC Adv. 2019;9(12):6460-81. https://doi.org/10.1039/C8RA08088G.

Mu X, Liang Q, Hu P, Ren K, Wang Y, Luo G. Selectively modified microfluidic chip for solvent extraction of radix salvia miltiorrhiza using three-phase laminar flow to provide double liquid-liquid interface area. Microfluid Nanofluid. 2010;9(2-3):365-73. https ://doi.org/10.1007/s10404-009-0554-y.

Noreen S, Dharmendra T, Zafar H, Bég OA. A numerical study of magnetohydrodynamic transport of nanofluids over a vertical stretching sheet with exponential temperature-dependent viscosity and buoyancy effects. Chem Phys Lett. 2016;661:20-30.

Ramesh G, Prabhu NK. Review of thermo-physical properties, wetting and heat transfer characteristics of nanofluids and their applicability in industrial quench heat treatment. Nanoscale Res Lett. 2011;6:334. https://doi.org/10.1186/1556-276X-6-334.

Soleimani H, Khurram BM, Yahya N, Khodapanah L, Sabet M, Demiral BMR, et al. Impact of carbon nanotubes based nanofluid on oil recovery efficiency using core flooding. Results Phys. 2018. https ://doi.org/10.1016/j.rinp.2018.01.072.

Soltanipour H, Khalilarya S, Motlagh SY, Mirzaee I. The effect of position-dependent magnetic field on nanofluid forced convective heat transfer and entropy generation in a microchannel. J Braz Soc Mech Sci Eng. 2016;39(1):1-11. https://doi.org/10.1007/s4043 $0-016-0541-7$. 
Wang Y, Hu A. Carbon quantum dots: synthesis, properties and applications. J Mater Chem C. 2014;2(34):6921-39. https://doi. org/10.1039/C4TC00988F.

Wu Y, Wang R, Dai C, XuY YT, Zhao M. Precisely tailoring bubble morphology in microchannel by nanoparticles self-assembly. Ind Eng Chem Res. 2019;58:3707-13. https://doi.org/10.1021/acs. iecr.8b06057.

Wu MB, Wang Y, Wu WT, Hu C, Wang XN, Zheng JT, et al. Preparation of functionalized water-soluble photoluminescent carbon quantum dots from petroleum coke. Carbon. 2014;78:480-9.

Zhang Z, He W, Zheng J, Wang G, Ji J. Rice husk ash-derived silica nanofluids: synthesis and stability study. Nanoscale Res Lett. 2016;11(1):502. https://doi.org/10.1186/s11671-016-1726-9.

Zhao MW, He HN, Dai CL, Sun YP, Fang YC, Liu YF, et al. Enhanced oil recovery study of a new mobility control system on the dynamic imbibition in a tight oil fracture network model. Energy
Fuels. 2018a;32:2908-15. https://doi.org/10.1021/acs.energyfuel s.7b03283.

Zhao MW, Lv WJ, Li YY, Dai CL, Wang XK, Zhou HD, et al. Study on the synergy between silica nanoparticles and surfactants for enhanced oil recovery during spontaneous imbibition. J Mol Liq. 2018b;261:373-8. https://doi.org/10.1016/j.molliq.2018.04.034.

Zhao MW, Wang RY, Dai CL, et al. Adsorption behaviour of surfactant-nanoparticles at the gas-liquid interface: influence of the alkane chain length. Chem Eng Sci. 2019;206:203-11.

Zhong XL, Yu X, Zhang Y, Liu XJ. Design of heat transfer experiment for nanofluid in diesel oil cooler. Trans Chin Soc Internal Combust Engines. 2011;29(1):67-71. https://doi.org/10.1007/ s12182-011-0123-3.

Zhou SQ, Ni R, Funfschilling D. Effects of shear rate and temperature on viscosity of alumina polyalphaolefins nanofluids. J Appl Phys. 2010;107(5):219. https://doi.org/10.1063/1.3309478. 